\title{
Antimicrobial agents - optimising the ecological balance
}

\author{
Sze-Ann Woon ${ }^{1}$ and Dale Fisher ${ }^{1,2,3^{*}}$
}

\begin{abstract}
Background: There is no more challenging a group of pharmaceuticals than antimicrobials. With the antibiotic era came great optimism as countless deaths were prevented from what were previously fatal conditions. Although antimicrobial resistance was quickly identified, the abundance of antibiotics entering the market helped cement attitudes of arrogance as the "battle against pestilence appeared won". Opposite emotions soon followed as many heralded the return of the pre-antibiotic era, suggesting that the "antibiotic pipeline had dried up" and that our existing armament would soon be rendered worthless.

Discussion: In reality, humans overrate their ecological importance. For millions of years there has been a balance between factors promoting bacterial survival and those disturbing it. The first half century of the "antibiotic era" was characterised by a cavalier attitude disturbing the natural balance; however, recent efforts have been made through several mechanisms to respond and re-strengthen the antimicrobial armament. Such mechanisms include a variety of incentives, educational efforts and negotiations. Today, there are many more "man-made" factors that will determine a new balance or state of ecological harmony.

Conclusion: Antibiotics are not a panacea nor will they ever be inutile. New resistance mechanisms will be identified and new antibiotics will be discovered, but most importantly, we must optimise our application of these extraordinary "biological tools"; therein lays our greatest challenge - creating a society that understands and respects the determinants of the effectiveness of antibiotics.
\end{abstract}

Keywords: Antibiotic stewardship, Antibiotic policy, Antibiotic pipeline, Antimicrobials, Antibiotics

\section{Background}

The discovery of penicillin brought great hope for the treatment of infectious diseases. However, two decades later, in the late 1940s, acceptance, mass production and distribution led to the advent of the concept with which we are all now very familiar - antimicrobial resistance (AMR). As other classes of antibiotics emerged, a similar pattern ensued from discovery through increasing utilisation to resistance. Poor infection control practices in healthcare settings facilitated the transmission of resistant organisms, amplifying the effect of antimicrobial usage. The healthcare industry responded with two major programmes - Infection Control in the 1980s and

\footnotetext{
*Correspondence: mdcfda@nus.edu.sg

'Division of Infectious Diseases, University Medicine Cluster, National

University Hospital, Singapore, Singapore

${ }^{2}$ Department of Medicine, Yong Loo Lin School of Medicine, National

University of Singapore, Singapore, Singapore

Full list of author information is available at the end of the article
}

Antimicrobial Stewardship in the last decade. These programs rely on the end user; however, while the importance of such global programmes cannot be disputed, these efforts alone are inadequate against the emergence of AMR.

If clinicians are to have an antimicrobial arsenal to treat infectious diseases, a combination of efforts to both preserve the value of what is currently available and to promote drug discovery is needed. Preservation of existing antimicrobials ultimately relies on minimising their use in all circumstances. In humans, there are many strategies to support this goal, including the implementation and adherence to guidelines provided by international organisations such as the World Health Organization (WHO) and the Centres for Disease Control and Prevention, by national bodies and individual institutions, as well as through the implementation of rapid (possibly point-of-care) diagnostic tests for AMR. Further, infection prevention activities also need to be implemented to minimise the need for treatment. 
In addition to direct human ingestion, animal husbandry is a major setting for antibiotic consumption that allows indirect human exposure to the same antibiotic or the resistant organisms (or their resistance genes) emerging via animals farmed as a source of food. The strategies to curb this are considerably more complex, requiring engagement of a number of non-medical players less appreciative of the ramifications of antibiotic misuse.

Drug discovery has suffered from a lack of exploitable bacterial binding sites, leading to the slow emergence of truly novel agents. Modifying existing antimicrobial agents to achieve theoretical benefits is often seen as commercially safer. Many pharmaceutical companies have shifted towards treatment of chronic conditions in order to lessen the financial risk. Therefore, this movement needs to be opposed with financial incentives and better protection for future and more novel antimicrobial discoveries. The antibiotic pipeline needs to be restored, but whether such efforts will be successful remains to be seen.

Along with the excessive morbidity and mortality, AMR poses a major economic burden, which helps justify the costs of AMR response programmes. In the United States (US), mortality from antimicrobial-resistant infections is reported at 23,000 deaths annually, with costs estimated at US\$ 26 billion [1]. In Europe, the annual hospital death rate is estimated at over 25,000 , with costs totalling more than EUR 900 million [2].

Humankind has enjoyed the capacity to treat bacterial infections for over 75 years. In this commentary, we present a number of efforts intended to help maintain this capacity moving forwards. These efforts could be regarded as more of a "bundle", where none will have significant benefit if implemented in isolation. AMR is a natural phenomenon - there are behaviours that stimulate it and responses that minimise it. The fear of "re-entering the pre-antibiotic era" is as unlikely as the eradication of antimicrobial-resistant organisms. We do, however, have some control over where on this spectrum the value of our antimicrobial armament will sit in the future. While the development of other classes of therapeutics relies on building on an existing knowledge base, in the world of antimicrobials, advances need to be made while simultaneously protecting the current therapeutic options from the very real threats to their effectiveness.

\section{Controlling AMR}

\section{Implementation of antimicrobial stewardship}

\section{programmes}

Bacteria are excellent at evolving mechanisms to counter the effects of antibacterial agents and this has been the way since ancient times, long before humans and modern medicine. Much has been written on the antibiotic resistosome, which has evolved from environmental bacteria and competitive pressure from other unicellular organisms in conjunction with the ability to receive genetic material both vertically (from "parent" bacteria) and horizontally from other organisms. Confronted with many mechanisms evident against all antimicrobials, it was time for a renewed respect for our relationship between microorganisms, antimicrobials and resistance mechanisms and drivers. In the human administration of antibiotics today, this is called stewardship.

Although the concept of antibiotic stewardship was raised in the 1980s, it had no validation until a randomised controlled study demonstrated that antibiotic use could be significantly reduced without adverse outcomes [3, 4]. Since then, it has grown and evolved into a prospective, formalised, multidisciplinary programme. Active interventions, such as discontinuing redundant antibiotics, transitioning from parenteral to oral therapy, optimising dose regimens and de-escalating from broad-spectrum to pathogen-directed therapies, have been shown to reduce costs and toxicity and prevent the selection of resistant organisms [5-7]. While the emergence of antibiotic-resistant organisms requires at least some antibiotic exposure, the relationship between the extent of use and resistance is less clear. It is intuitive that reducing antibiotic use is key to countering this natural phenomenon; however, social factors, including government corruption, have been postulated as more valid [8]. It is likely that corruption is a surrogate for poor behaviour in terms of stewardship, infection control, public health and the necessary government controls to affect and monitor healthcare and agricultural systems driving the spread of resistant organisms.

This lack of clarity of the benefits of a solitary intervention, such as antibiotic stewardship programmes, should not deter us from the very likely benefit (and at a minimum, lack of harm) of it as part of a holistic multipronged response. Although efforts have been made internationally to encourage such programs, this is still primarily limited to acute care settings and tertiary centres where there are infectious disease physicians or microbiologist champions. However, to optimise future benefits, programmes must be effective in all healthcare settings, including outpatients, aged care, peripheral/ rural hospitals, the community and, importantly, animal husbandry. Stewardship practices should not be limited to antimicrobials used for treatment, but should include those used for prophylaxis, which vary considerably and are not supported by evidence. The role of good stewardship can be undermined when attention is excessively directed to seemingly more tangible strategies such as reinforcing the pipeline of new antibiotics. A balanced approach is required.

\section{Non-prescription antibiotics}

Non-prescription, over-the-counter antimicrobial access occurs worldwide, particularly in Asia and Southern 
Europe [9]. This is associated with frequent adverse events, masking of underlying infection and a contribution to the issue of increasing AMR as its use does not take into account a qualified clinical opinion and local susceptibility patterns. Although the contribution of non-prescription antibiotic use to the worldwide spread of resistance is not known, it has been speculated to play an important role in producing high levels of resistance in those communities. In Chile [10] and Korea [11], improved regulation of nonprescription antibiotics has been associated with improved resistance profiles. Not only can the consumed antibiotic be the wrong choice, but there is evidence that the use of expired [12], counterfeit [13, 14] and inappropriately low antimicrobial doses [15-17], which are common associations, contribute further to the risk of treatment failure and resistance. Self-medication is a potentially important alternative to formal consultations, particularly in low-resource settings; however, in reality, such access to medication without a prescription is usually a cultural and system issue, as doctors are often available. In most populations, this issue can be resolved, but not without controversy. The challenges in changing this practice lie not only in implementing legislation that will prevent the use of over-the-counter antibiotics but increased awareness through educational interventions and, most importantly, easy access to professional help and affordable drugs.

\section{Reducing antibiotic use in animals and agriculture}

Agriculture and food animals are important sources of AMR as they are exposed to enormous quantities of antibiotics and serve as a reservoir of antibiotic-resistance genes. Antibiotics have been used in animal husbandry, veterinary medicine and agriculture to prevent, control and treat infections for over 60 years. Antibiotic use in growth promotion is, however, controversial. It was discovered that small sub-therapeutic doses of penicillin and tetracycline could enhance weight gain by about $15-20 \%$, although the underlying mechanism of this action remains unclear [18-21]. Sweden became the first country to ban antimicrobial use as growth promoters followed by Denmark and Germany. The implementation of a European Union-wide ban occurred in 2006 [22]. Partial restriction exists in countries such as Mexico, South Korea, Taiwan and Hong Kong; however, widespread use of antimicrobial growth promoters still occur in the majority of the world. Transmission of resistance occurs through the food chain, through contact with people working with animals, such as farmers, and through manure-contaminated environments. The recent report of plasmid-mediated colistin resistance genes found in slaughtered pigs, raw food and humans highlights the risk of transmission from animals to humans [23]. Efforts have been made by some countries, including the US, to phase out the use of antibiotics in animal feeds. Regulating and raising awareness and support amongst farmers, food producers and retailers have taken place; yet, more still needs to be done globally [24]. There are many possible options for supporting the concerns of the farming community while reducing their antimicrobial use. These include establishing standardised universal surveillance of antibiotic use and resistance, ensuring appropriate training and prudent use of antibiotics, expanding the range of vaccines available for veterinary use, using phage therapy (the neutralisation of foodborne pathogens in animals [25] and control of plant pathogens [26]), and using predatory bacteria in combating pathogenic bacteria $[27,28]$.

\section{Reviving the antibiotic pipeline}

Antibiotic discovery was strong from the 1940s to 1960s, but slowed for some decades until the introduction of linezolid in 2000 and daptomycin in 2003 [29]. Most of the early antibiotics were discovered by screening soil-derived actinomycetes; yet, over time, this source became exhausted and no longer provided novel compounds or a further understanding of the mechanisms of action. Efforts have since been redirected to producing synthetic antibiotics by modification of existing drugs to produce active analogues, but this has led to limited benefits. The subsequent development of high-tech platforms based on genomics and combinational chemistry, such as high-throughput screening and rational drug design, were employed but failed to identify compounds with effective antibacterial activity [30]. The number of large multinational pharmaceutical companies actively developing antibiotics declined as a result of this lack of progress in the field along with the financial risks.

Drug discovery and development is conventionally driven by financial motivation. For the private industry, aligning to an antimicrobial programme has more risk than other pharmacological fields. Taking new drugs to market requires considerable testing for safety and efficacy in each indication sought. Once resistance ensues, the clinical, and therefore commercial, value of the product falls. In the medical profession, physicians try to limit a new antibiotic's utilisation to maintain its clinical value; however, paradoxically, this affects sales, in effect creating another disincentive to drug discovery. When these new drugs are used in infectious disease management they have a short-term curative application as opposed to drugs used in the treatment of chronic diseases. It is no wonder that this "antibiotic pipeline" is weak and requires support from government and non-government sectors.

\section{Supporting the discovery and development of new antimicrobial drugs}

Recognising the waning value of the antimicrobial armament, in 2004, the Infectious Diseases Society of America proposed legislative, regulatory and funding solutions to 
counteract barriers in the development of new antibiotics [31]. These included tax incentives for development of priority antibiotics, measured liability protections, revising existing guidelines for clinical trials involving new antibiotics, and supporting public/private partnerships to increase funding. The so-called antibiotic pipeline could not flourish relying on conventional market forces alone, and the last decade or so has seen considerable attention to legislative support (Fig. 1). The extent of these efforts in supporting drug discovery was unprecedented.

The $10 \times$ ' 20 campaign, launched by the Infectious Diseases Society of America in 2010, called for the development and approval of 10 novel antibiotics by 2020 [29]. The Global Action Plan by WHO aims to improve awareness of AMR, strengthen knowledge through surveillance and research, reduce the incidence of infection, optimise the use of antimicrobial agents and increase investment in new drugs, diagnostic tools and vaccines [32]. The O'Neil Review on Antimicrobial Resistance by Prime Minister David Cameron in the United Kingdom [33] and the release of the National Action Plan for Combating Antibiotic Resistant Bacteria by President Barack Obama [34], highlight the high level support for these efforts and augment the global response.

Many other initiatives and collaborations have recently been established to create new models for antibiotic development via incentive strategies. These include the provision of subsidies to lower antibiotic research costs for drugs with a large market, high potential sales and low risks. Sharing of scientific databases would facilitate collaboration between developers, minimising duplication and facilitating the dissemination of new information. Funding training and development of individuals specialising in research and development of antibiotics is key, as is financial support for small companies that are likely to produce marketable products but lack the capital to do so [35-37]. The European Commission's Innovative Medicines Initiative [38] is a large public-private incentive programme supporting the rapid development of effective drugs through which the New Drugs for Bad Bugs (ND4BB) initiative [39] and, subsequently, the DRIVE-AB programme [40] were established with the aim of facilitating antibiotic discovery and development through various collaborations.

Another strategy was to compensate successful development as a way to motivate developers. The Generating Antibiotic Incentives Now Act was ratified in October 2012 by the US government and aimed to incentivize antibiotic discovery [41]. This included granting an additional 5 years of market exclusivity for antibiotics developed to treat serious infections, termed the qualified infectious disease product, and an additional 6 months for development of a companion rapid diagnostic test. This bill also entitled the new drug to priority review and fast-track approval, which in turn committed the Food and Drug Administration (FDA) to review its clinical trial guidelines and review processes. In addition, a streamlined clinical trial process for novel antibiotics, the Limited Population Antibacterial Drug approval, allows potential drugs to be studied via smaller, faster and less expensive trials [42]. Following this, a proposed US bill, the 21st Century Cures Act, offers qualified antibiotics Limited Population Antibacterial Drug approval and the option of transferable market exclusivity for up to 12 months, where the purchasers are required to donate a portion of the returns to AMR research and patient access programmes [43].

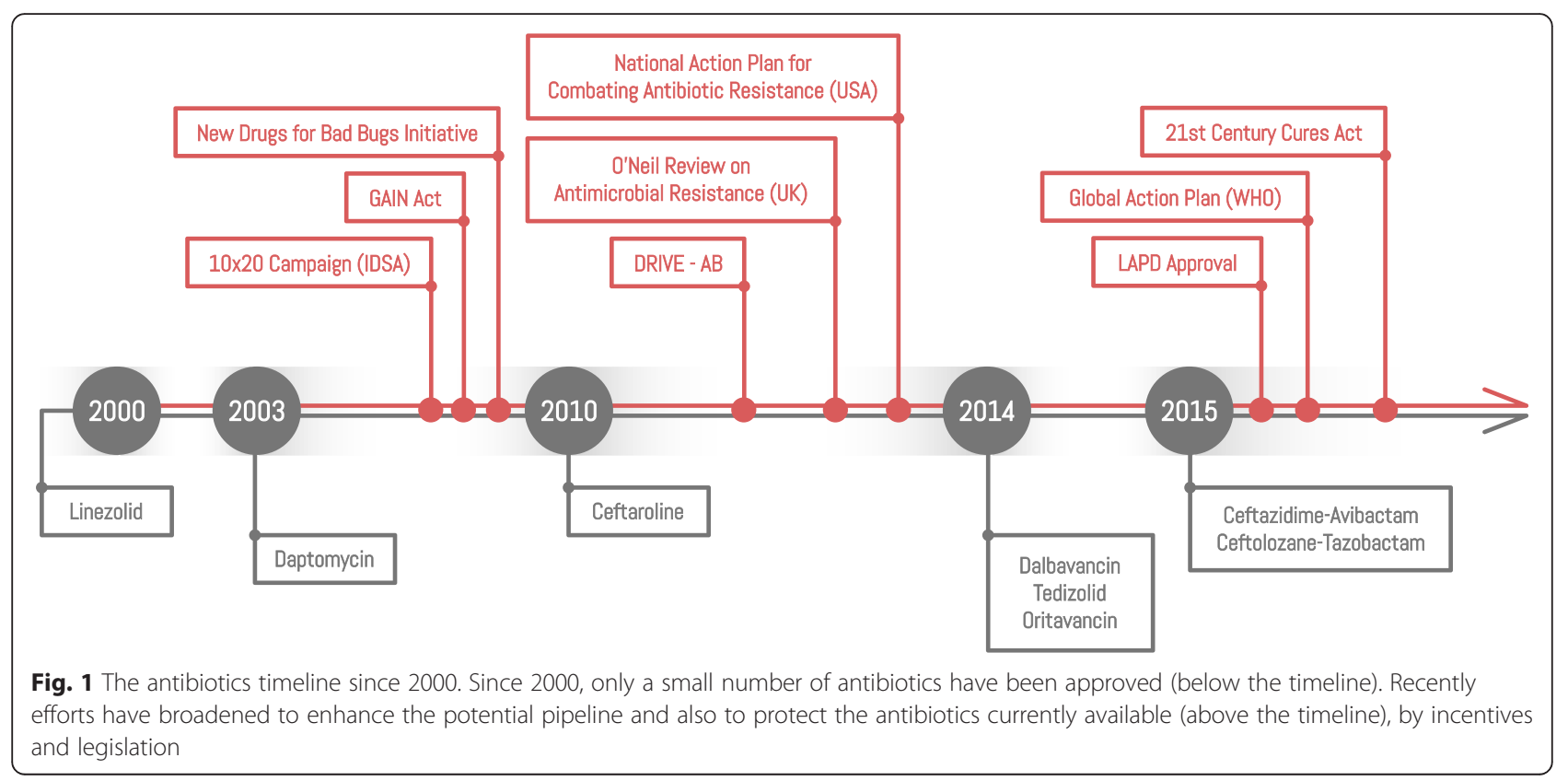


Perhaps a more well-rounded model is the WHO's Global Consortium [44, 45], which provides support at the drug discovery stage via an open source platform as well as grants for academics. It aims to lower development costs and risk using patent buy-outs of successfully developed antibiotics (which facilitates antibiotic stewardship and negates the need for excessive marketing), funding of clinical trials and advance purchase commitments for generic distribution.

Additionally, many business models and incentive strategies have been proposed, with some placing emphasis on investment at the beginning of drug development while others reward only successful development of a drug [46]. Nevertheless, a successful package not only requires the creation of a supportive environment for investment that increases profitability and aligns both public and private priorities, but should also address public health objectives such as promoting antibiotic stewardship and improving patient access to new (potentially expensive) antibiotics.

\section{What's new in the pipeline?}

Since the approval of telavancin in 2009 and ceftaroline in 2010, five new antibiotics have been approved by the FDA, three of which have mainly gram-positive activity and two directed against gram-negative pathogens. Oritavancin and dalbavancin are long-acting, synthetic lipoglycopeptides with activity against methicillin-resistant Staphylococcus aureus and vancomycin-resistant Enterococcus, and are approved for treatment of acute bacterial skin and skin structure infections [47-49]. Tedizolid, an oxazolidinone-class antibiotic similar to linezolid, is licensed for treatment of these infections [50], with treatment for other indications underway, including hospital-acquired pneumonia. While these new drugs have the advantage of being utilised in the outpatient setting, thus avoiding prolonged intravenous use and length of hospital stay, they are still costly and questions remain as to their utility in the treatment of more serious clinical infections such as bacteraemia, endocarditis, osteomyelitis and device-related infections. Ceftolozane/ tazobactam and ceftazidime/avibactam are approved for treatment of complicated intra-abdominal and urinary tract infections; nevertheless, the latter is only approved for use in patients with limited or no treatment options as it was the first drug to go through the recommended regulatory pathway and deemed to be an "unmet medical need drug" [51-53]. Both antibiotics have activity against extended spectrum beta-lactamases, AmpC producers and multi-drug resistant Pseudomonas aeruginosa, but only ceftazidime/avibactam has activity against Class A carbapenemases.

In May 2016, the Pew Charitable Trust, which maintains a regularly updated antibiotic pipeline, described
37 new antibiotics in development, of which 11 were in phase I clinical trials, 13 in phase II and 13 in phase III [54]. About a third of these have the potential to treat infections caused by Enterococcus faecium, Staphylococcus aureus, Klebsiella pneumoniae, Acinetobacter baumannii, Pseudomonas aeruginosa and Enterobacter spp (ESKAPE pathogens), and just over a third have activity against drug-resistant gonorrhoea, Clostridium difficile and carbapenem-resistant Enterobacteriaceae, which are pathogens considered an "urgent threat" by the Centres for Disease Control and Prevention [1]. Of drugs in phase III, only about $60 \%$ will typically reach FDA approval level and only about half of these are active against gramnegative pathogens. Notably, none have promising activity against carbapenem-resistant Acinetobacter sp. or the Class D metallo-beta-lactamases (e.g. NDM-1) [54]. Of the 37 antibiotics, very few have a novel mechanism of action and none of these are yet in phase III studies. Nonetheless, there is reason for optimism in both the short and long term.

Bacteriophage treatment is a largely untested approach to antibacterial therapy and represents a revival of a previous option. These viruses infect and rapidly kill specific target bacteria. Nevertheless, none are in therapeutic practise although many are in development and at various stages of clinical trials [55]. Bacteriophages may prove to be novel antimicrobial agents with potential use in decolonisation or treatment of infection alone or in association with conventional antibiotics, and there is also specific potential for their use in infections complicated by biofilm formation. The side effect profile needs to stand the test of time, but the few studies to date suggest a good safety profile [56].

\section{A renewed hope for antibiotic discovery?}

In January 2015, a group of scientists from Northeastern University, MA, described their discovery of an antibiotic, teixobactin, with a completely different chemical scaffold to that of existing antibiotics. It has gram-positive activity, which works through binding to precursors of bacterial cell wall polymers and appears to have no inducible resistance. This discovery involved a novel technology called iChip [57], a miniaturised, multichannel device that allowed antibiotic-producing soil bacteria to be cultivated and identified in their natural environment. Scouring the soil for new antimicrobial molecules has proven to be extremely challenging in the last decade as soil microorganisms cannot be grown under traditional laboratory conditions. This innovation can hopefully be applied to identify promising molecules with novel mechanisms of action.

\section{Improving affordability and improving patient access to antibiotics}

When a new antibiotic reaches the end of the arduous pipeline and is registered, the traditional patent-based 
pharmaceutical model grants developers market exclusivity for a number of years, following which generic manufacturers are permitted development and marketing opportunities to the drug. During these early years with the patent in place, the pharmaceutical organisation has a window period to obtain financial returns for the research and development, clinical trials and notoriously expensive marketing, as well as shareholder profit; they control the market geographically and they control price. Most patients cannot benefit from drugs that are not distributed globally and financial returns are not usually found in low- and middle-income countries. In fact, most patients in high-income countries will struggle with meeting the costs as individuals; drugs not yet recognised in national pharmaceutical benefit systems or by insurers may lead to excessive costs for individuals even in these countries.

It is a "double-edged sword", where we wish to improve access, yet not to the point where excessive use drives high levels of resistance. Any programme that improves access to individuals in need should build-in measures that minimise inappropriate use. The current model potentially creates incentive to encourage any consumption of the antibiotic, but only to those individuals and countries that can pay. In the last decade or so, several systems have provided remarkable contributions to access in low- and middle-income countries on a large scale, including the Global Fund (for malaria, tuberculosis and HIV), The Presidents Emergency Fund for AIDS Relief (PEPFAR) and the Global Alliance for Vaccines and Immunisation (GAVI). Ideally, similar efforts in the name of antibiotic access could ensue via negotiation and bulk purchasing or via subsidy. The crucial effort lies in delinking profits from sales volume. The scale of the antibiotic issue is different and the situation more complex, but some efforts have been initiated; examples include the Antibiotic Health Impact Fund, Antibiotics as Public Goods, and the Rewarding Antibiotic Development and Responsible Stewardship Programme, where antibiotics could be offered at a marginal cost and overall profitability of projects is tied to global health impact $[46,58]$. Whilst still providing developers with a concrete return, it removes the motivation to oversupply the market, incentivises developers to distribute their new antibiotics, and facilitates access to those who need them most. Other strategies include patent buy-outs to successfully developed antibiotics and sales of a license for unlimited access to antibiotics at a small cost, hence allowing fair distribution, increased affordability and equitable access [58].

\section{Raising awareness and changing prescribing patterns and behaviour}

There is no doubt that inappropriate antibiotic use is a significant contributor to the emergence of resistance $[59,60]$. It has been suggested that $20-50 \%$ of prescribing is unnecessary. In primary care, antibiotics are frequently

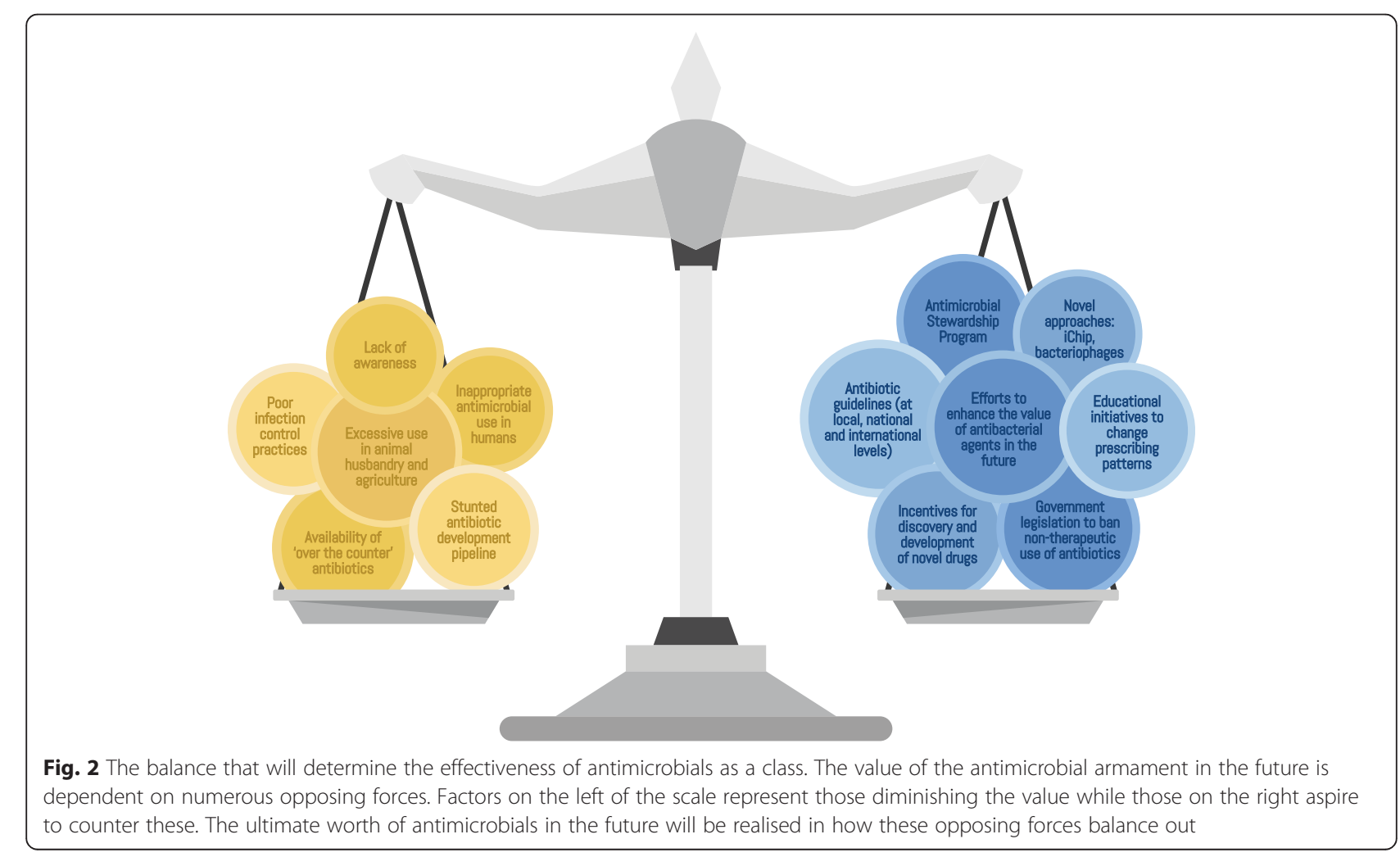


prescribed for upper respiratory tract symptoms and the treatment of asymptomatic bacteriuria is associated with a higher prevalence of resistant organisms [61-64]. The prescription and use of antibiotics is influenced by a complex interplay of knowledge and attitudes of the prescriber and patient (and in the case of animal husbandry, the farmer). Patients who expect a prescription are more likely to get one $[65,66]$. Many doctors would admit that patients' expectations, peer pressure, fear of litigation, poor knowledge of microbiology and underutilisation of available guidelines play a role in driving poor antibiotic use $[62,67]$. Few clinicians see the bigger picture, the antibiograms, the national epidemic curves, etc.; however, all prescribers and users are contributors to the evolving quantum of multidrug-resistant infections. There needs to be an increased awareness that the imprudent use of antibiotics does not usually exert its effect at an individual level, but to the society as a whole, with serious public health implications. A recent WHO assessment revealed that there is a lack of awareness among both the public and healthcare workers in this matter [68]. Several interventions to improve antibiotic use targeting both the public as well as healthcare providers, particularly multimodal campaigns, have shown positive outcomes in terms of adherence to guidelines and reduction of inappropriate prescription [69-71]. However, it remains unclear whether the effectiveness of these campaigns as well as the change in practice and behaviour are sustainable. Multifaceted mass media and educational campaigns targeting both the public and healthcare professionals, but culturally tailored to the particular community, should be held with active engagement of all levels of authority. This should be performed in a coordinated and comprehensive manner that addresses all aspects of behaviour such as capability, opportunity and motivation [72]; changing health behaviour is difficult and requires significant and sustained commitment and investment.

\section{Conclusion}

Antibiotics are unique therapeutics and a human resource. They are the only drug class that, when used in an individual, it can affect others. Their misuse has resulted in a shift in the ecological balance between resistant and susceptible strains in the flora of humans, animals and the environment, and there are several determinants of where the balance will settle (Fig. 2). As healthcare providers, we hope for sensitive strains and highly effective antibiotics. The best outcome for the most favourable balance lies in a multisystem approach to the handling of antibiotics.

The urgent call to curb AMR requires efforts at all levels - governments, healthcare providers, pharmaceutical companies, veterinary and agriculture sectors, and the general public. We can be very optimistic about current deliberate efforts, including the expansion of stewardship in human medicine, animals and agriculture, changing regulations, and creating incentives that promote the discovery of truly novel drugs, as well as ensuring global access to antibiotics. Global society as a collective must share the same perspective of the issues and the vision required to work towards maintaining a strong antimicrobial armament. Antibiotics are a unique biological tool that demands respect, as does any form of Nature. Humans have only recently begun to influence the ecologic balance between antibacterials, bacteria and the resistance mechanisms they display. There is an increasing current understanding that we can favourably restore the balance that preserves and enhances the value of this critical therapeutic class.

\section{Abbreviations}

FDA, Food and drug administration; WHO, World health organization

\section{Acknowledgements}

We thank Vanessa Teo for assistance with the figures.

\section{Authors' contributions}

This was an invited manuscript to DF, who outlined and set the scope and objectives. SW undertook the literature review and wrote the first draft. Both authors contributed to subsequent drafts and revisions, and read and approved the final manuscript.

\section{Competing interests}

The authors declare that they have no competing interests.

\section{Author details}

'Division of Infectious Diseases, University Medicine Cluster, National University Hospital, Singapore, Singapore. ${ }^{2}$ Department of Medicine, Yong Loo Lin School of Medicine, National University of Singapore, Singapore, Singapore. ${ }^{3}$ National University Health System, NUHS Tower Block, 1 E Kent Ridge Road, Level 10, Singapore 119228, Singapore.

Received: 7 April 2016 Accepted: 27 July 2016

Published online: 05 August 2016

\section{References}

1. Centers for Disease Control and Prevention (CDC). Antibiotic Resistance Threats in the United States. 2013. http://www.cdc.gov/drugresistance/ threat-report-2013/pdf/ar-threats-2013-508.pdf. Accessed 11 July 2016.

2. European Centre for Disease Prevention and Control (ECDC). The bacterial challenge: time to react. A Call to Narrow the Gap Between MultidrugResistant Bacteria in the EU and the Development of New Antibacterial Agents. ECDC/EMEA Joint Technical Report. 2009. http://ecdc.europa.eu/en/ publications/Publications/0909_TER_The_Bacterial_Challenge_Time_to_ React.pdf. Accessed 11 July 2016.

3. Briceland LL, Nightingale $\mathrm{CH}$, Quintiliani R, Cooper BW, Smith KS. Antibiotic streamlining from combination therapy to monotherapy utilizing an interdisciplinary approach. Arch Intern Med. 1988;148:2019-22.

4. Fraser GL, Stogsdill P, Dickens Jr JD, Wennberg DE, Smith Jr RP, Prato BS. Antibiotic optimization. An evaluation of patient safety and economic outcomes. Arch Intern Med. 1997;157:1689-94.

5. Fraser GL, Stogsdill P, Owens Jr RC. Antimicrobial stewardship initiatives: a programmatic approach to optimizing antimicrobial use. In: Owens Jr RC, Ambrose PG, Nightingale CH, editors. Antibiotic Optimization: Concepts and Strategies in Clinical Practice. 1st ed. New York: Marcel Dekker; 2005. p. 261-326.

6. Glowacki RC, Schwartz DN, Itokazu GS, Wisniewski MF, Kieszkowski P, Weinstein RA. Antibiotic combinations with redundant antimicrobial spectra: clinical epidemiology and pilot intervention of computer-assisted surveillance. Clin Infect Dis. 2003;37:59-64. 
7. Owens Jr RC, Fraser GL, Stogsdill P. Antimicrobial stewardship programmes as a means to optimize antimicrobial use. Insights from the Society of Infectious Diseases Pharmacists. Pharmacotherapy. 2004;24:896-908.

8. Collignon P, Athukorala PC, Senanayake S, Khan F. Antimicrobial resistance: the major contribution of poor governance and corruption to this growing problem. PLoS One. 2015;10(3), e0116746.

9. Morgan DJ, Okeke IN, Laxminarayan R, Perencevich EN, Weisenberg S. Non-prescription antimicrobial use worldwide: a systematic review. Lancet Infect Dis. 2011;11(9):692-701.

10. Bavestrello L, Cabello A, Casanova D. Impact of regulatory measures in the trends of community consumption of antibiotics in Chile. Rev Med Chil. 2002;130:1265-72.

11. Park S, Soumerai SB, Adams AS, Finkelstein JA, Jang S, Ross-Degnan D. Antibiotic use following a Korean national policy to prohibit medication dispensing by physicians. Health Policy Plan. 2005;20:302-9.

12. Okeke IN, Lamikanra A. Quality and bioavailability of tetracycline capsules in a Nigerian semiurban community. Int J Antimicrob Agents. 1995;5:245-50.

13. Taylor RB, Shakoor O, Behrens RH. Drug quality, a contributor to drug resistance? Lancet. 1995:346:122.

14. Land T. Combating counterfeit drugs. Nature. 1992;355:192.

15. Thamlikitkul V. Antibiotic dispensing by drug store personnel in Bangkok. Thailand J Antimicrob Chemother. 1988;21:125-31.

16. Bartoloni A, Cutts F, Leoni S, Austin CC, Mantella A, Guglielmetti P, et al. Patterns of antimicrobial use and antimicrobial resistance among healthy children in Bolivia. Trop Med Int Health. 1998;3:116-23.

17. Awad A, Eltayeb I, Matowe L, Thalib L. Self-medication with antibiotics and antimalarials in the community of Khartoum state. Sudan J Pharm Pharm Sci. 2005:8:326-31.

18. Stokstad ELR, Jukes TH. Further observations on the "animal protein factor.". Proc Soc Exp Biol Med. 1950;73(3):523-8.

19. Stahly TS, Cromwell GL, Monegue HJ. Effects of dietary inclusion of copper and(or) antibiotics on the performance of weanling pigs. J Anim Sci. 1980;51:1347-51.

20. Cho I, Yamanishi S, Cox L, Methé BA, Zavadil J, Li K, et al. Antibiotics in early life alter the murine colonic microbiome and adiposity. Nature. 2012;488:621-6.

21. Alexander TW, Yanke LJ, Topp E, Olson ME, Read RR, Morck DW, McAllister TA. Effect of subtherapeutic administration of antibiotics on the prevalence of antibiotic-resistant Escherichia coli bacteria in feedlot cattle. Appl Environ Microbiol. 2008;74(14):4405-16.

22. Maron DF, Smith TJ, Nachman KE. Restrictions on antimicrobial use in food animal production: an international regulatory and economic survey. Global Health. 2013;9:48.

23. Liu Y-Y, Wang T, Walsh TR, Yi LX, Zhang R, Spencer J, et al. Emergence of plasmid-mediated colistin resistance mechanism MCR-1 in animals and human beings in China: a microbiological and molecular biological study. Lancet Infect Dis. 2016;16(2):161-8. doi:10.1016/S1473-3099(15)00424-7.

24. Lowes R. Obama Takes Antibiotics Fight From Pharmacy to Farm. Medscape Jun. 2015;02. http://www.medscape.com/viewarticle/845820. Accessed 11 July 2016.

25. Goodridge LD, Bisha B. Phage-based biocontrol strategies to reduce foodborne pathogens in foods. Bacteriophage. 2011;1(3):130-7.

26. Balogh $B$, Jones JB, Iriarte FB, Momol MT. Phage therapy for plant disease control. Curr Pharm Biotechnol. 2010;11(1):48-57.

27. Kadouri DE, To K, Shanks RM, Doi Y. Predatory bacteria: a potential ally against multidrug-resistant Gram-negative pathogens. PLoS One. 2013;8(5), e63397.

28. Allen HK, Trachsel J, Looft T, Casey TA. Finding alternatives to antibiotics. Ann N Y Acad Sci. 2014;1323(1):91-100.

29. Boucher HW, Talbot GH, Benjamin Jr DK, Bradley J, Guidos RJ, Jones RN, et al. 10 × '20 Progress - development of new drugs active against gramnegative bacilli: an update from the Infectious Diseases Society of America. Clin Infect Dis. 2013;56(12):1685-94.

30. Lewis K. Platforms for antibiotic discovery. Nat Rev Drug Discov. 2013;12(5):371-87.

31. The Infectious Diseases Society of America (IDSA). Bad bugs, no drugs: as antibiotic discovery stagnates, a public health crisis brews. 2004. http:// www.idsociety.org/uploadedFiles/IDSA/Policy_and_Advocacy/Current_ Topics_and_Issues/Advancing_Product_Research_and_Development/Bad_ Bugs_No_Drugs/Statements/As\%20Antibiotic\%20Discovery\%20Stagnates\% 20A\%20Public\%20Health\%20Crisis\%20Brews.pdf. Accessed 11 July 2016.

32. World Health Organization. Draft global action plan on antimicrobial resistance. 2015. http://www.who.int/drugresistance/global_action_plan/ ongoing_activities/en. Accessed 11 July 2016.
33. Review on Antimicrobial Resistance. Tackling a global health crisis: initial steps. 2015. http://amr-review.org/sites/default/files/Report-52.15.pdf. Accessed 11 July 2016.

34. The White House. National action plan for combatting antibiotic resistant bacteria. 2015. https:/mww.whitehouse.gov/sites/default/files/docs/national_ action_plan_for_combating_antibotic-resistant_bacteria.pdf. Accessed 11 July 2016.

35. Mossialos E, Morel CM, Edwards S, Berenson J, Gemmill-Toyama M, Brogan D. Policies and Incentives for Promoting Innovation in Antibiotic Research, European Observatory on Health Systems and Policies. 2010. http://www.euro.who.int/_ data/assets/pdf_file/0011/120143/E94241.pdf. Accessed 11 July 2016.

36. Morel CM, Mossialos E. Stoking the antibiotic pipeline. BMJ. 2010;340:C2115.

37. Munos B. Can open-source R\&D reinvigorate drug research? Nat Rev Drug Discov. 2006:5:723-9.

38. Innovative Medicines Initiative. The Innovative Medicines Initiative. 2015. http://www.imi.europa.eu/. Accessed 11 July 2016.

39. New Drugs for Bad Bugs. Combating antibiotic resistance: New Drugs for Bad Bugs. 2015. http://www.nd4bb.eu. Accessed 11 July 2016.

40. DRIVE-AB. DRIVE-AB: Re-investment in R\&D and responsible antibiotic use. 2014. http://drive-ab.eu. Accessed 11 July 2016.

41. US Congress. Generating Antibiotic Incentives Now Act of 2011. 112th Cong., H.R. 2182/S. 1734. https://www.govtrack.us/congress/bills/112/hr2182. Accessed 11 July 2016.

42. Infectious Diseases Society of America. Limited population antibacterial drug (LPAD) approval mechanism. 2012. http://www.idsociety.org/2012 lpad_proposal_backing. Accessed 11 July 2016.

43. Energy US, Committee C. 21st Century Cures Act Discussion Document White Paper, 114th US Congress. 2015. http://energycommerce.house.gov/ sites/republicans.energycommerce.house.gov/files/114/Analysis/Cures/ 20150127-Cures-Discussion-Document.pdf. Accessed 11 July 2016

44. Kieny M. Current WHO Model for Development/Preservation of New Antibiotics. Technical Consultation on Innovative Models for New Antibiotics' Development and Preservation. 2014. http://who.int/phi/ implementation/9_current_who_model_for_development_preservation_ new antibiotics.pdf?ua=1. Accessed 11 July 2016.

45. Kieny M. A Publicly Financed Global Consortium for R\&D to Fight Antibiotic Resistance. Technical Consultation on Innovative Models for New Antibiotics' Development and Preservation. 2014. http://www.who.int/phi/ implementation/9_infobrief_current_who_model_for_development_ preservation_new_antibiotics.pdf. Accessed 11 July 2016.

46. Renwick MJ, Brogan DM, Mossialos E. A systematic review and critical assessment of incentive strategies for discovery and development of novel antibiotics. J Antibiot (Tokyo). 2016;69(2):73-88. doi:10.1038/ja.2015.98.

47. Boucher HW, Wilcox M, Talbot GH, Puttagunta S, Dunne MW. Once-weekly dalbavancin versus daily conventional therapy for skin infection. N Engl J Med. 2014:370:2169-79.

48. Corey GR, Kabler H, Mehra P, Gupta S, Overcash JS, Porwal A, et al. Single-dose oritavancin in the treatment of acute bacterial skin infections. N Engl J Med. 2014;370:2180-90.

49. Corey GR, Good S, Jiang H, Moeck G, Wikler M, Green S, et al. Single-dose oritavancin versus 7-10 days of vancomycin in the treatment of gram-positive acute bacterial skin and skin structure infections: the SOLO II noninferiority study. Clin Infect Dis. 2015;60(2):254-62.

50. Moran GJ, Fang E, Corey GR, Das AF, De Anda C, Prokocimer P. Tedizolid for 6 days versus linezolid for 10 days for acute bacterial skin and skin-structure infections (ESTABLISH-2): a randomised, double-blind, phase 3, non-inferiority trial. Lancet Infect Dis. 2014;14:696-705.

51. Lucasti C, Hershberger E, Miller B, Yankelev S, Steenbergen J, Friedland I, Solomkin J. Multicenter, double-blind, randomized, phase II trial to assess the safety and efficacy of ceftolozane-tazobactam plus metronidazole compared with meropenem in adult patients with complicated intraabdominal infections. Antimicrob Agents Chemother. 2014;58(9):5350-7.

52. Wagenlehner FM, Umeh O, Steenbergen J, Yuan G, Darouiche RO. Ceftolozane-tazobactam compared with levofloxacin in the treatment of complicated urinary-tract infections, including pyelonephritis: a randomised, double-blind, phase 3 trial (ASPECT-CUTI). Lancet. 2015;385(9981):1949-56.

53. Mawal Y, Critchley IA, Riccobene TA, Talley AK. Ceftazidime-avibactam for the treatment of complicated urinary tract infections and complicated intra-abdominal infections. Expert Rev Clin Pharmacol. 2015;8(6):691-707.

54. The Pew Charitable Trusts. Tracking the Pipeline of Antibiotics in Development. http://www.pewtrusts.org/en/research-and-analysis/issue-briefs/2014/03/12/ tracking-the-pipeline-of-antibiotics-in-development. Accessed 11 July 2016. 
55. Sansom C. Phage therapy for severe infections tested in the first multicentre trial. Lancet Infect Dis. 2015;15:1384-5.

56. Viertel T, Ritter K, Horz H. Viruses versus bacteria-novel approaches to phage therapy as a tool against multidrug-resistant pathogens. J Antimicrob Chemother. 2014;69(9):2326-36.

57. Ling LL, Schneider T, Peoples AJ, Spoering AL, Engels I, Conlon BP, et al. A new antibiotic kills pathogens without detectable resistance. Nature. 2015;517:455-9.

58. Outterson K. New Business Models for Sustainable Antibiotics, Chatham House 2014. http://www.chathamhouse.org/sites/files/chathamhouse/public/Research/ Global\%20Health/0214SustainableAntibiotics.pdf. Accessed 11 July 2016.

59. Lipsitch M, Samore MH. Antimicrobial use and antimicrobial resistance: a population perspective. Emerg Infect Dis. 2002:8:347-54.

60. Harbarth S, Samore MH. Antimicrobial resistance determinants and future control. Emerg Infect Dis. 2005:11:794-801.

61. Gonzales R, Malone DC, Maselli JH, Sande MA. Excessive antibiotic use for acute respiratory infections in the United States. Clin Infect Dis. 2001;33:757-62.

62. Akkerman AE, Kuyvenhoven MM, van der Wouden JC, Verheij TJ. Analysis of under- and overprescribing of antibiotics in acute otitis media in general practice. J Antimicrob Chemother. 2005;56:569-74.

63. Sarkar P, Gould IM. Antimicrobial agents are societal drugs. How should this influence prescribing? Drugs. 2006;66(7):893-901.

64. Cai T, Nesi G, Mazzoli S, Meacci F, Lanzafame P, Caciagli P, et al. Asymptomatic bacteriuria treatment is associated with a higher prevalence of antibiotic resistant strains in women with urinary tract infections. Clin Inf Dis. 2015;61(11):1655-61.

65. Butler CC, Rollnick S, Pill R, Maggs-Rapport F, Stott N. Understanding the culture of prescribing: qualitative study of general practitioners' and patients' perceptions of antibiotics for sore throats. BMJ. 1998;317:637-42.

66. Scott JG, Cohen D, DiCicco-Bloom B, Orzano AJ, Jaen CR, Crabtree BF. Antibiotic use in acute respiratory infections and the ways patients pressure physicians for a prescription. J Fam Pract. 2001;50:853-58.

67. Lam TP, Lam KF. What are the non-biomedical reasons which make family doctors over-prescribe antibiotics for upper respiratory tract infection in a mixed private/public Asian setting? J Clin Pharm Ther. 2003;28(3):197-201.

68. World Health Organization. Worldwide Country Situation Analysis: Response to Antimicrobial Resistance. http://www.who.int/drugresistance/ documents/situationanalysis/en/. Accessed 11 July 2016.

69. Roque F, Herdeiro MT, Soares S, Teixeira Rodrigues A, Breitenfeld L, Figueiras A. Educational interventions to improve prescription and dispensing of antibiotics: a systematic review. BMC Public Health. 2014;14:1276.

70. Huttner B, Goossens H, Verheij T, Harbarth S. Characteristics and outcomes of public campaigns aimed at improving the use of antibiotics in outpatients in high-income countries. Lancet Infect Dis. 2010;10:17-31.

71. Lambert MF, Masters GA, Brent SL. Can mass media campaigns change antimicrobial prescribing? A regional evaluation study. J Antimicrob Chemother. 2007:59:537-43.

72. Michie S, van Stralen M, West R. The behaviour change wheel: a new method for characterising and designing behaviour change interventions. Implement Sci. 2011;6:42.

\section{Submit your next manuscript to BioMed Central and we will help you at every step:}

- We accept pre-submission inquiries

- Our selector tool helps you to find the most relevant journal

- We provide round the clock customer support

- Convenient online submission

- Thorough peer review

- Inclusion in PubMed and all major indexing services

- Maximum visibility for your research

Submit your manuscript at www.biomedcentral.com/submit

) Biomed Central 